\title{
PAKOM PEMANFAATAN SAMPAH RUMAH TANGGA DI PONDOK PESANTREN AL-AHAD DAN BUDI UTOMO SURAKARTA
}

\author{
${ }^{1)}$ Haryanto, ${ }^{2)}$ Muchlison Anis, ${ }^{3)}$ Eni Budiyati \\ ${ }^{1), 2), 3}$ Fakultas Teknik, Universitas Muhammadiyah Surakarta \\ 1) email : haryanto_ar@ums.ac.id \\ ${ }^{2)}$ email:m_anis@ums.ac.id \\ ${ }^{3)}$ email :Eni.Budiyati@ums.ac.id
}

\begin{abstract}
Beautiful environment will be created, if any of the issues that both household waste from kitchen and garden can be managed properly. Community Service activities at boarding school (pesantren) Al-Ahad and Budi Utomo Surakarta Education and Training in the form of composting household waste. Activities run smoothly, residents can follow the spirit Ponpes community and composer to function properly. The resulting compost to fertilize plants, making the environment look beautiful, comfortable and people get an extra income.
\end{abstract}

Keywords: garbage, compost, value-added

\section{PENDAHULUAN}

Selama ini sampah merupakan masalah utama di semua kota, sebab sampah apabila tidak dimanfaatkan dengan baik dapatmenjadi acaman yang serius bagi kelangsungan dan kelestarian fungsi lingkungan. Sebaliknya, apabila dimanfaatkan dengan baik, sampah bernilai potensial, misalnya sebagai penyedia lapangan pekerjaan, penigkatan kualitas dan estetika lingkungan, serta dapat juga diolah menjadi bahan pembuatan kompos untuk memperbaiki lahan kritis di berbagai daerah di Indonesia.

Dampak yang ditimbulkan sampah yang tidak dimanfaatkan dengan baik diantaranya menurunnya kualitas dan estetika lingkungan yang disebabkan bau dan kotor serta dapat menyebabkan gangguan kesehatan. Sebab timbunan sampah dapat menjadi media berkembang biak serangga dan mikroorganisme yang menyebabkan berbagai macam penyakit.

Hal yang sama juga terjadi di lingkungan Pondok Pesantren (Ponpes) Al Ahad Mojosongo dan Budi Utomo Kadipiro. Di kedua lokasi tersebut Sampah Rumah
Tangga (SRT) belum dimanfaatkan dengan baik dan hanya mengandalkan pada petugas pengambil sampah yang datang setiap 3-4 hari sekali. Pemahaman warga masyarakat di ketiga lokasi ini terhadap konsep pengelolaan sampah dengan $3 \mathrm{R}$ (reduce, reuse, dan recycle) masih kurang. Akibat yang ditimbulkan produksi SRT, hampir semuanya hanya dibuang ke Tempat Pembuangan Akhir (TPA) memerlukan biaya yang cukup besar.

Pondok pesantren merupakan lingkungan dimana masyarakat biasanya berperilaku tertib dan disiplin. Pada saat ini lingkungan pondok pesantren belum dimanfaatkan dengan baik. Oleh karena itu perlu pemeliharaan dan pemberdayaan agar potensi kawasan tersebut dapat dilihat, dinikmati, dipelajari dan dijadikan contoh oleh masyarakart sekitar, terutama anak-anak santri Ponpes di Mojosongo Jebres maupun di Kadipiro Banjarsari.

Luas area lingkungan Ponpes di Mojosongo, dan di Kadipiro masing-masing sekitar 2 dan 4 ha. Dua wilayah ini mempunyai kesamaan yaitu merupakan wilayah komplek dengan kepadatan penduduk yang cukup 
tinggi, sedangkan perbedaannya adalah di Ponpes Mojosongo terletak di Perumnas, sehingga semua lahan sudah dibangun rumah, sedangkan di Ponpes Budi Utomo Kadipiro masih banyak kapling tanah yang belum dibangun. Dengan perbedaan pada saat ini dan kesamaan di waktu mendatang, pengalaman penataan dengan PAKOM ini dapat dijadikan referensi untuk penataan di lingkungan Ponpes dan masyarakat pada umumnya.

Menurut Peraturan Daerah (Perda), Ruang Terbuka Hijau (RTH) pada suatu kawasan minimal 30\%. Untuk memenuhi standar tersebut, maka harus diusahakan RTH 0,3 ha untuk kawasan Ponpes Al Ahad dan 1 ha untuk kawasan Ponpes Budi Utomo. Apabila RTH tersebut dapat diwujudkan, maka keindahan taman dan hasil tanaman produktif di lingkungan Ponpes dapat dinikmati oleh warga penghuni Ponpes maupun warga sekitarnya, serta dapat ikut berperan dalam pelestarian fungsi lingkungan.

Memperhatikan permasalah di atas, masyarakat lingkungan Ponpes menyadaridan bersemangat untuk mewujudkan lingkungan yang bersih dan sehat, taman yang indah dan mempunyai tanaman produktif yang dapat dimanfaatkan warga. Model pengelolaan SRT yang sudah berhasil diterapkan di beberapa kawasan antara lain: (1) Dilakukan oleh masyarakat sendiri; (2) Memberikan keuntungan nyata bagi masyarakat (produktif); (3) Menyelesaikan semua jenis dan masalah sampah (komprehensif); (4) Ramah lingkungan.

Sampai dengan April 2012 lingkungan Ponpes Al Ahad dan Budi Utomo Surakarta dihuni oleh 396 jiwa. Lingkungan Ponpes merupakan kawasan yang sudah jadi dan perlu ditata ulang, agar warga dapat hidup dengan lebih nyaman dan sejahtera. Dengan cara ini diharapkan lingkungan Ponpes nantinya mempunyai 30\% RTH, sehingga dapat meningkatkan daya dukung pada kehidupan warga, khususnya masalah air tanah dan lingkungan yang bersih, sehat, indah, nyaman dan produktif.
Tujuan pelaksanaan Pengabdian Masyarakat di Ponpes Al Ahad dan Budi Utomo Surakarta adalah memberikan kesadaran dan kemampuan kepada warga Ponpes untuk mengolah sampah organik dari dapur dan pekarangan menjadi kompos.dan anorganik.

Adapun manfaatnya antara lain: (1) Tersedianya pupuk kompos (organik) untuk keperluan penghijauan di lingkungan Ponpes Al Ahad dan Budi Utomo; (2) Tertatanya lingkungan Ponpes Al Ahad dan Budi Utomo menjadi lingkungan yang bersih, indah, nyaman-teduh, dan warga betah tinggal di rumah; (3) Warga lingkungan mendapat tambahan penghasilan dari tanaman produktif; (4) Meningkatnya daya dukung lingkungan atas kehidupan warga lingkungan Ponpes Al Ahad dan Budi Utomo.

\section{METODE PELAKSANAAN KEGIATAN}

Tahapan pelaksanaan Pengabdian kepada Masyarakat (PAKOM) ini sebagai berikut:

1. Musyawarah dengan penanggungjawab mitra Pimpinan Ponpes Al Ahad Mojosongo dan Budi Utomo Kadipiro untuk mendapatkan profil mitra dalam rangka mengetahui kebutuhan anggotanya.

2. Hasilnya diajukan sebagai Proposal PAKOM dengan mitra Ponpes Al Ahad dan Budi Utomo Surakarta.

3. Setelah Proposal dinyatakan didanai, diadakan koordinasi dengan Pimpinan Ponpes Al Ahad dan Budi Utomo Surakarta untuk menentukan waktu, materi (acara) dan sarana yang diperlukan untuk pelaksanaan PAKOM.

4. Sosialisasi pelaksanaan PAKOM kepada Pengurus dan Santri Ponpes Al Ahad dan Budi Utomo Surakarta

5. Pelaksanaan PAKOM berupa Pendidikan dan Pelatihan bagi Pengurus dan Santri serta warga di sekitar Ponpes Al Ahad dan Budi Utomo Surakarta serta pengadaan serta pengoperasian komposter. 


\section{HASIL PELAKSANAAN KEGIATAN}

Hasil yang diperoleh dari program Pengabdian Masyarakat ini antara lain Pengurus dan Santri lingkungan Ponpes Al Ahad dan Budi Utomo Surakarta telah:

1. Menyadari pentingnya mengelola sampah rumah tangga baik yang berasal dari dapur maupun pekarangan yang diawali dengan pemilahan berdasarkan jenis sampah. Sampah di pondok dapat dikelompokkan menjadi sampah rumah tangga dan sampah yang terserak di jalan-jalan di sekitar lingkungan pondok. Langkah pertama sebelum mengolah sampah adalah memilah sampah organik (sisa makanan, sayuran, kulit buah-buahan, daun dll.) dan anorganik (kertas, plastik, kaca, logam dll.). Mengubah sampah organik menjadi kompos, adalah salah satu cara mengatasi masalah sampah di perumahan.

Tetapi beberapa jenis sampah organik tidak disarankan dibuat kompos, antara lain berupa daging, ikan, kulit udang, tulang, susu, keju, lemak atau minyak, karena akan bau dan mengundang serangga seperti lalat dan pada proses pengomposan timbul belatung. Sampah ini juga mengundang anjing dan kucing untuk mengaisnya. Kotoran anjing dan kucing, kemungkinan membawa penyakit. Tanaman yang berhama atau gulma, karena hama atau bijinya masih terkandung dalam kompos, sehingga berpotensi menular pada tanaman yang dipupuk dengan hasil pupuk komposnya.

Pemilahan sampah: Sampah organik yang berupa sisa makanan, kulit buah, sisa sayuran dicacah $2 \times 2 \mathrm{~cm}$. Sisa sayur matang yang mengandung santan dibilas dulu, ditiriskan. Tulang, daging, lemak, minyak, disisihkan karena mengganggu proses pengomposan.

2. Dapat praktek membuat kompos dari sampah rumah tangga dengan biaya yang murah (starter dibuat dari sisa buah dan gula tebu). Fungsi starter adalah membantu proses pengomposan dengan bantuan bakteri pengurai yang ada didalamnya. Hanya digunakan sekali pada awal pengomposan.
Mikroba yang terdapat dalam starter akan membantu menguraikan ikatan-ikatan kimia kompleks menjadi sederhana.

Dalam pembuatan kompos ini kami memanfaatkan MOL (Mikroorganisme Lokal) sebagai strater. MOL merupakan bakteri buatan kita (lokal) untuk menyuburkan tanah atau untuk menguraikan sampah organik menjadi kompos. Berguna seperti nutrisi (vitamin) bagi tanah agar tetap subur. MOL adalah kumpulan mikroorganisme yang bisa "diternakkan" fungsinya dalam konsep "zero waste" adalah sebagai starter pembuatan kompos organik. Dengan MOL ini maka konsep pengomposan bisa selesai dalam waktu 3 mingguan (Sobirin 2008).

Keunggulan utama penggunaan MOL adalah murah, selain itu ada beberapa keuntungan: (a) Mendukung pertanian ramah lingkungan; (b) Dapat mengatasi permasalahan limbah rumah tangga; (c) Pembuatan serta aplikasinya mudah dilakukan; (d) Mengandung unsur kompleks dan mikroba yang bermanfaat dalam produk pupuk dan dekomposer organik yang dihasilkan

Proses pembuatan kompos aerob dilakukan dalam komposter diletakkan di tempat terbuka dengan sirkulasi udara yang baik. Karakter dan jenis bahan baku yang cocok untuk pengomposan aerob adalah material organik yang mempunyai perbandingan unsur karbon (C) dan nitrogen (N) kecil (dibawah 30:1), kadar air 40-50\% dan $\mathrm{pH}$ sekitar 6-8. Contohnya adalah hijauan leguminosa (daun-daunan), sisa sayuran mentah, jerami, gedebog pisang dan kotoran unggas.

Apabila kekurangan bahan yang megandung karbon, bisa ditambahkan arang sekam padi ke dalam adonan pupuk. Waktu membuat kompos aerob memerlukan waktu 40-50 hari, sehingga diperlukan ketelatenan lebih untuk membuat kompos dengan metode ini. Kita harus mengontrol dengan seksama suhu dan kelembaban kompos saat proses pengomposan berlangsung. Secara berkala, tumpukan kompos harus dibalik untuk menyetabilkan suhu dan kelembabannya. 
Berikut ini cara membuat kompos aerob yang dilakukan:

a. Menyiapkan komposter dari ember plastik besar (lampiran) untuk pelaksanaan pengomposan. Lebih baik diletakkan di tempat yang teduh untuk menghindari hujan.

b. Menyiapkan material organik dari sisasisa tanaman, sisa sayuran dapur, daun hasil menyapu, bisa juga dicampur dengan kotoran ternak. Cacah bahan organik tersebut hingga menjadi potongan-potongan kecil. Semakin kecil potongan bahan organik semakin baik. Namun jangan sampai terlalu halus, agar aerasi bisa berlangsung sempurna saat pengomposan berlangsung.

c. Masukan bahan organik yang sudah dicacah ke dalam komposter, kemudidan padatkan. Isi seluruh bak kayu hingga penuh.

d. Menyiram bahan baku kompos yang sudah tersusun dalam komposter dengan starter untuk memberikan kelembaban. Untuk mempercepat proses pengomposan bisa ditambahkan starter mikroorganisme pembusuk ke dalam tumpukan kompos tersebut. Setelah itu diatasnya bisa ditambahkan lagi bahanbahan organik lainnya. Dilakukan terus hingga ketinggian kompos sekitar 0,80 dari tinggi bagian dala komposter.

e. Setelah 24 jam, suhu tumpukan kompos akan naik hingga $650 \mathrm{C}$, keadaan yang panas ini dibiarkan hingga 2-4 hari. Fungsinya untuk membunuh bakteri patogen, jamur dan gulma. Perlu diperhatikan, proses pembiaran jangan sampai lebih dari 4 hari. Karena berpotensi membunuh mikroorganisme pengurai kompos. Apabila mikroorganisme dekomposer ikut mati, kompos akan lebih lama matangnya.

f. Setelah hari ke-4, suhu diturunkan untuk mencegah kematian mikroorganisme dekomposer. Suhu optimum pengomposan dijaga pada kisaran 45$60^{\circ} \mathrm{C}$ dan kelembaban pada $40-50 \%$. Cara menjaga suhu adalah dengan membolak-balik kompos, sedangkan untuk menjaga kelembaban siram kompos dengan air. Pada kondisi ini penguapan relatif tinggi, untuk mencegahnya kita bisa menutup tumpukan kompos dengan menutup dan melindungi kompos dari siraman air hujan.

g. Cara membalik kompos sebaiknya dilakukan dengan mengusahkan massa kompos yang bagian bawah dapat pindah ke bagian atas dan sebaliknya. Demikian pula massa kompos yang ditengah dapat pindah ke bagian tepi dan sebaliknya. Dengan begitu, semua kompos dipastikan sudah terbalik semua. Proses pembalikan sebaiknya dilakukan setiap 3 hari sekali sampai proses pengomposan selesai. Atau balik apabila suhu dan kelembaban melebihi batas yang ditentukan.

h. Apabila suhu sudah stabil dibawah 45oC, warna kompos hitam kecoklatan dan volume menyusut hingga 50\% hentikan proses pembalikan. Selanjutnya adalah proses pematangan selama 14 hari.

i. Secara teoritis, proses pengomposan selesai setelah 40-50 hari. Namun kenyataannya bisa lebih cepat atau lebih lambat tergantung dari keadaan dekomposer dan bahan baku kompos. Pupuk kompos yang telah matang dicirikan dengan warnanya yang hitam kecoklatan, teksturnya gembur, tidak berbau.

j. Untuk memperbaiki penampilan(apabila pupuk kompos hendak dijual) dan agar bisa disimpan lama, sebaiknya kompos diayak dan di kemas dalam karung. Simpan pupuk kompos di tempat kering dan teduh.

3. Menata lingkungan sehingga terlihat lebih estetis. Pupuk organik adalah pupuk yang tersusun dari materi makhluk hidup, seperti pelapukan sisa-sisa tanaman, hewan, dan manusia. Pupuk organik dapat berbentuk padat atau cair yang digunakan untuk memperbaiki sifat fisik, kimia, dan 
biologi tanah. Pupuk organik mengandung banyak bahan organik daripada kadar haranya. Sumber bahan organik dapat berupa kompos, pupuk hijau, pupuk kandang, sisa panen (jerami, brangkasan, tongkol jagung, bagas tebu, dan sabut kelapa), limbah ternak, limbah industri yang menggunakan bahan pertanian, dan limbah kota (sampah). Pencemaran lingkungan berhubungan erat dengan sampah karena sampah merupakan sumber pencemaran. Permasalahan sampah timbul karena tidak seimbangnya produksi sampah dengan pengolahannya dan semakin menurunnya daya dukung alam sebagai tempat pembuangan sampah.

Salah satu alternatif pengolahan sampah adalah memilih sampah organik dan memprosesnya menjadi pupuk organik berupa kompos atau pupuk hijau. Manfaat pupuk organik meliputi: (a) Meningkatkan produksi pertanian baik kualitas maupun kuantitas; (b) Mengurangi pencemaran lingkungan; (c) Meningkatkan kualitas lahan secara berkelanjutan; (d) Meningkatkan produktivitas lahan dan dapat mencegah degradasi lahan; (e) Memperbaiki sifat fisika, kimia biologi tanah serta lingkungan. Berperan sebagai sumber energi dan makanan mikroba tanah sehingga dapat meningkatkan aktivitas mikroba tersebut dalam penyediaan hara tanaman.

Penambahan bahan organik berpengaruh pada pertumbuhan tanaman. Hal ini disebabkan karena adanya senyawa yang berpengaruh terhadap aktivitas biologis di dalam tanah. Senyawa tersebut meliputi senyawa perangsang tumbuh (auxin), dan vitamin. Senyawa-senyawa ini di dalam tanah berasal dari eksudat tanaman, pupuk kandang, kompos, sisa tanaman dan juga berasal dari hasil aktivitas mikrobia dalam tanah. Di samping itu, diindikasikan asam organik dengan berat molekul rendah, terutama bikarbonat (seperti suksinat, ciannamat, fumarat) hasil dekomposisi bahan organik, dalam konsentrasi rendah dapat mempunyai sifat seperti senyawa perangsang tumbuh, sehingga berpengaruh positip terhadap pertumbuhan tanaman.
Kandungan bahan organik tanah merupakan ciri penting suatu tanah, karena bahan organik tanah mempengaruhi sifat-sifat tanah melalui berbagai cara. Hasil perombakan bahan organik mampu mempercepat proses pelapukan bahan-bahan mineral tanah; distribusi bahan organik di dalam tanah berpengaruh terhadap pemilahan (differentiation) horison. Komponen pupuk organik yang paling berpengaruh terhadap sifat kimiawi tanah adalah kandungan humusnya. Humus dalam kompos mengandung unsur hara yang dibutuhkan tanaman. Humus yang menjadi asam humat atau jenis asam lainnya dapat melarutkan zat besi (Fe) dan alumunium (Al) sehingga fosfat yang terikat besi dan alumunium akan lepas dan diserap oleh tanaman. Selain itu humus merupakan penyangga kation yang dapat mempertahankan unsur hara sebagai bahan makanan untuk tanaman.

Penataan lingkungan Ponpes ASRI agar memenuhi 4 (empat) unsur yaitu keindahan, kenyamanan, kerindangan dan kebersihan dilakukan dengan meningkatkan partisipasi warga dengan:

a. Warga mengadakan sarasehan secara rutin sekali dalam satu bulan sehingga warga menyepakati hal-hal yang akan dilakukan dalam satu bula ke depan dan mengevaluasi hal-hal yang sudah disepakati pada sarasehan bulan sebelumnya.

b. Warga mengadakan kerja bakti secara rutin sebulan sekali sebagai bentuk eksekusi hasil sarasehan yang telah dilakukan.

c. Dibentuk kelompok-kelompok santri Ponpes (satu kelompok 5 santri), kemudian masing-masing kelompok diberi tugas sesuai dengan aktivitas yang mendukung terwujudnya lingkungan yang asri, seperti menyediakan sejumlah tempat sampah untuk memilah sampah, membuat kompos, menanam tanaman yang produktif di pekarangan, pot atau pinggir jalan, memupuk tanaman produktif, menyiangi tanaman, memanen hasil dari tanaman. 


\section{KESIMPULAN}

Program Pengabdian Masyarakat kompetitif di lingkungan Ponpes Al Ahad dan
Budi Utomo Surakarta telah berjalan dengan baik dan bermanfaat bagi warga Ponpes dan masyarakat sekitarnya.

\section{DAFTAR PUSTAKA}

Anonim, 2012, Cara buat Pupuk Kompos, http:/www.kebonkembang.com/kegiatan/cara-buatpupuk-kompos.html

Anonim, 2013, Petunjuk Teknis Penataan Lingkungan Permukiman Berbasis Komunitas (PLPBK), Direktorat Jenderal Cipta Karya - Kementerian Pekerjaan Umum RI.

Febrianti W., 2013, Cara budidaya pohon pisang, http://windafebriyantiwicho.blogspot. com/2013/10/cara-budidaya-pohon-pisang.html

Handoyo R., 2013, Menanam pohon, solusi untuk lingkungan dan investasi untuk penanam, http://www.mitrabibit.com/2013/09/menanam-pohon-solusi-untuk-lingkungan.html

Hanna G., 2008, Pembuatan Kompos dari Sampah Rumah Tangga, http://www.kebonkembang. $\mathrm{com} /$ panduan-dan-tip-rubrik-35/221-pembuatan-kompos-dari-sampah-rumah-tangga. html

Karina P., 2012,Hijau di Atas Limbah, http://www.kebonkembang.com/serba-serbi-rubrik-44/ hijau-di-atas-limbah.html 